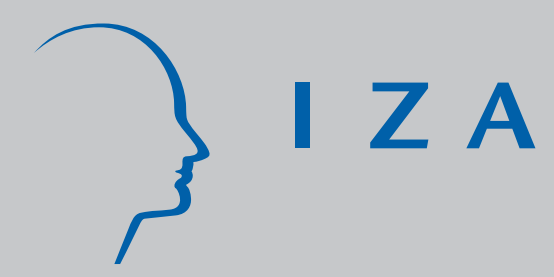

IZA DP No. 3678

Culture and Human Capital Investments: Evidence of an Unconditional Cash Transfer Program in Bolivia

Monica Yanez-Pagans

September 2008 


\title{
Culture and Human Capital Investments: Evidence of an Unconditional Cash Transfer Program in Bolivia
}

\author{
Monica Yanez-Pagans \\ University of Illinois at Urbana-Champaign \\ and IZA
}

Discussion Paper No. 3678

September 2008

\author{
IZA \\ P.O. Box 7240 \\ 53072 Bonn \\ Germany \\ Phone: +49-228-3894-0 \\ Fax: +49-228-3894-180 \\ E-mail: iza@iza.org
}

Any opinions expressed here are those of the author(s) and not those of IZA. Research published in this series may include views on policy, but the institute itself takes no institutional policy positions.

The Institute for the Study of Labor (IZA) in Bonn is a local and virtual international research center and a place of communication between science, politics and business. IZA is an independent nonprofit organization supported by Deutsche Post World Net. The center is associated with the University of Bonn and offers a stimulating research environment through its international network, workshops and conferences, data service, project support, research visits and doctoral program. IZA engages in (i) original and internationally competitive research in all fields of labor economics, (ii) development of policy concepts, and (iii) dissemination of research results and concepts to the interested public.

IZA Discussion Papers often represent preliminary work and are circulated to encourage discussion. Citation of such a paper should account for its provisional character. A revised version may be available directly from the author. 


\section{ABSTRACT \\ Culture and Human Capital Investments: Evidence of an Unconditional Cash Transfer Program in Bolivia}

This paper uses a policy quasi-experiment created by the introduction of an old-age unconditional cash transfer program in Bolivia to study the intra-household income allocation process towards children's educational expenditure by ethnicity and gender of the recipient. Taking advantage of a sharp discontinuity created by the program assignment mechanism, I investigate the heterogeneity in the patterns of allocation within indigenous, multiethnic, and non-indigenous families, conditional on having one elder and one school-age child living in the household. I find that cultural factors (proxied by ethnicity) count in the decision making process of human capital investments. In particular, the allocation of resources within indigenous families follows rules closely related to patriarchal family structures (in which women have limited decision-making power) and is consistent with unitary, dictatorial, and common preferences theoretical household models. Conversely, non-indigenous families follow decision rules more closely related to collective and bargaining behavior models.

JEL Classification: H55, O15, I12, D12

Keywords: Bolivia, culture, Bolivida, educational expenditure

Corresponding author:

Monica Yanez-Pagans

Department of Agricultural and Consumer Economics

University of Illinois at Urbana-Champaign

1301 West Gregory Dr

Urbana, IL 61801

USA

E-mail: myanezp2@illinois.edu

\footnotetext{
" I am indebted to Gustavo Canavire for useful discussions about the survey design, sampling, and data collection. I am also very grateful to Carl Nelson, Mary Arends-Kuenning, Ugo Panizza, María Cecilia Calderón, Patricia Yáñez-Pagans, Stas Kolenikov, Felipe Barrera-Osorio, Denise Arnold, Madhu Khanna, Bruce Sherrick, Gerald Nelson, Mevlude Akbulut-Yuksel, Giedrius Blazys, and participants at the IZA Summer School and the Impact Evaluation Network for helpful comments and suggestions. The usual caveats apply.
} 


\section{Introduction}

The creation of an old-age unconditional cash transfer program in Bolivia (Bolivida) sets up a quasi experimental opportunity to study the intra-household income allocation process towards children's human capital investments in Bolivia. As the probability of receiving this transfer changes discontinuously at the eligibility age, this sharp discontinuity is used to parametrically identify conditional average intent-to-treat effects and to study income allocation patterns across ethnicities and gender. The main contribution of the paper is presenting evidence of culture-dependent intra-household resource allocation in Bolivia.

The impact of this program is measured by estimating a reduced-form equation linking child-level educational expenditure with household-level program eligibility, after controlling for socioeconomic and demographic characteristics. The eligibility effect (which I allow to vary over households and children) is assumed to be a linear function of the ethnicity and gender of the potential recipient. The core finding is that Bolivida transfers to women lead to substantial improvements in children's human capital investments. As far as ethnicity, eligibility leads to lower increases on schooling investments among indigenous households compared to their non-indigenous counterparts. This is consistent with the hypothesis that returns to education are lower among indigenous people (Psacharopoulos (1993) and Gasparini, Marchionni, and Gutierrez (2004)) and fits into a model of intertemporal rational expectations formation.

Martínez (2004) evaluates the effect of this unconditional cash transfer on household food expenditure by geographical location and gender of the recipient. He finds that the pension has a positive effect on the consumption of householdproduced agricultural products; the effect is equivalent to one and a half times the value of the pension. He concludes therefore that the program is promoting productive investments that ultimately create a multiplier effect on household food consumption.

The intrahousehold allocation of old-age pension programs has been analyzed in different contexts and settings. The most widely studied pension program by far is the South African means-tested "Old-Age Pension Program". Case and Deaton (1998) investigate the standards of living of those families who have a member that receives the pension. They find that the program is well targeted as far as it is reaching the poorest households. They also analyze the redistributive consequences of the transfer on food, clothing, housing, schooling, transport, health, and adult goods expenditure by head-of-the-household's gender. Their paper finds that the pension is spent similarly to any other income except that there are gender-specific expenditure patterns. Duflo (2003) analyzes the impact of this same program on children's weight-for-height and height-for-age. She finds that both variables are dramatically improved among girls when their grandmothers receive the transfer, but that their nutrition is entirely unaffected when the pension is received by their grandfathers. The paper does not find any 
significant effect of the pension on boys. Finally, Edmonds (2006) analyzes the impact of the South African program on child labor and schooling responses. He finds large increases in schooling attendance and reductions in child labor when a member in the household becomes eligible, particularly if this potential recipient is a black male. In the context of Latin America, de Carvalho Filho (2000) studies the effect of a Social Security Reform on child labor and school enrollment in Brazil. He finds that girls and boys enroll more in school and reduce labor market participation as a result of a exogenous variation in income introduced by this reform.

\section{Bolivia, Ethnicity and Cultural Diversity}

Bolivia is the poorest country in South America and second only to Nicaragua in Latin America. In 1999, 41 percent of its population was living below the national poverty line (Barja, Monterrey, and Villarroel, 2004). The elderly and youngest have traditionally been the most vulnerable and unprotected segments. Poverty indicators by age show that while only 37 percent of adults are poor, a disproportionate 49 percent of the children and the elderly live in poverty (Udape and Unicef, 2005).

Bolivia has a complex and unusual multiethnic dimension, only comparable to Guatemala, Peru and Ecuador within Latin America and the Caribbean. Bolivia is the country with the highest percentage of indigenous population in the Region; 62 percent of Bolivians identified themselves as belonging to an indigenous group in the last Census in 2001. This ethnic dimension is closely related to the income distribution; while close to 49 percent of indigenous people live below the poverty line, only 24 percent of the non-indigenous are poor (Udape, 2006). However, cultural disparities among ethnic groups are important and go far beyond the income distribution. While the most obvious observable differences lie in race and language, there indeed exist profound differences in traditions, values, and beliefs which might derive in different decision-making rules for the allocation of resources within households. In particular, patriarchal family structures, which are more common among indigenous families, might limit the power of indigenous women to allocate their resources as compared to non-indigenous women. ${ }^{1}$

\section{The Bolivida Old-Age Pension Program}

In the middle of the 1990s, an array of unprecedented (and still controversial) economic and social structural reforms were implemented by the Bolivian Gov-

\footnotetext{
${ }^{1}$ For a description of family structures among ethnic groups in Bolivia see Larson, Harris, and Tandeter (1995), and Stephenson (1999).
} 
ernment with the aim of confronting a long-term stagnation of the economy. One of these reforms was the so called the "Capitalization", which sold half of the six largest state-owned companies (including telecommunications, hydrocarbons, air transportation, railroad industries, electrical energy, and smelting companies) to private investors. Another of these reforms was the Pension System Reform, which eliminated the old publicly administered pay-as-you-go system, implemented the current privately managed system, and created an old-age unconditional cash transfer program which entitled all Bolivians aged 65 and older to receive a flat, noncontributory, and unconditional cash transfer independently of their income levels (i.e. the only eligibility rule is age). The Government targeted this segment of the population as it had traditionally been one of the most unprotected and vulnerable ones (coverage in Bolivia is one of the lowest in the Region; close to 80 percent of Bolivians have no access to the pension system, Yanez-Pagans and Landa (2007)).

The unique feature of the Bolivian pension reform however was not the creation of this unconditional cash transfer program, but rather its association with the privatization process. As the Capitalization was expected to generate considerable revenues for the country, the Government determined that this pension would be financed with the dividends of the shares of the capitalized companies. The amount of the benefit was originally set up as an annuity of USD248 and it has been used since then as a mechanism to redistribute the gains of the Capitalization among the elderly Bolivians.

The Program was strategically introduced in 1997 before the elections with the name of Bono Solidario (Bonosol). After the elections, a new administration took office and had to deal with the fact that the transition costs of the reform were higher, and dividends of the capitalized companies lower, than originally expected. The liquidity problems were so serious that in 1998 the program had to be put on hold for a couple of years as payments were financially untenable. In 2001, the amount of the pension was reduced to annuities of USD120 (approximately 50 percent of its original value), and the program resumed under the name of Bolivida ${ }^{2}$ (further discussion can be found in Dowers, Fassina, and Pettinato (2001), Barja and Urquiola (2003), and Rofman (2006)).

Bolivida is a large Program as far as the amount of money transferred to the households. von Gersdorff (1997) estimated that the transfers accounted for 50 and 85 percent of the annual income of the poor and extremely poor households, respectively. Table 1 shows the amount of the benefit as a proportion of total per capita expenditure across ethnic groups. On average, Bolivida represents 7 percent of the total per capita expenditure of indigenous families (ranging from 2 to 99 percent across the expenditure distribution), and 4 percent of the total per capita expenditure of non-indigenous families (ranging from 1 to 43 percent across the analogous distribution).

\footnotetext{
${ }^{2}$ Bolivida payments began on December 20th of 2000 . The payment was split into two payments of US60 each and where paid on December 2000 and April 2001, Martínez (2004).
} 
Table 1: Bolivida as proportion of total per capita expenditure ${ }^{a}$

\begin{tabular}{|c|c|c|c|c|}
\hline \multirow[t]{2}{*}{ Percentile } & Mean PCE & Share Bolivida (\%) & Mean PCE & Share Bolivida (\%) \\
\hline & \multicolumn{2}{|c|}{ Indigenous } & \multicolumn{2}{|c|}{ Non-indigenous } \\
\hline 1 & 30 & 99 & 79 & 43 \\
\hline 5 & 39 & 44 & 98 & 27 \\
\hline 10 & 83 & 35 & 181 & 5 \\
\hline 25 & 120 & 16 & 200 & 9 \\
\hline 50 & 217 & 7 & 403 & 4 \\
\hline 75 & 321 & 7 & 734 & 3 \\
\hline 90 & 583 & 3 & 1,246 & 2 \\
\hline 95 & 805 & 3 & 1,670 & 1 \\
\hline 99 & 1,715 & 2 & 2,774 & 1 \\
\hline
\end{tabular}

$a$ Percentiles are based on total per capita expenditure. Total per capita expenditure (PCE) adjusted for equivalence scales.

Table 2 presents estimates of who the beneficiaries of Bolivida are. Though take-up is high at the margin of eligibility, compliance is far from perfect. The coefficient of 0.630 for indigenous eligible men indicates that only 63 percent of this segment of the population is receiving the program. On average, 26 percent of eligibles are not receiving this income they are entitled to by Law. Several possible explanations for the existence of this non-trivial proportion of non-compliers are discussed in Section 6.1 along with its implications for the identification strategy. It is reassuring though that no ineligible is benefiting from the program (assuming of course that age is truthfully reported and measured without error).

Table 2: Share of age group receiving Bolivida ${ }^{a}$

\begin{tabular}{|lcc|}
\hline & Indigenous & Non-indigenous \\
\hline Panel A : Male & & \\
$55-59$ & & \\
& 0.000 & 0.000 \\
$60-64$ & $(-)$ & $(-)$ \\
& 0.000 & 0.000 \\
$65-74$ & $(-)$ & $(-)$ \\
& $0.630^{* * *}$ & $0.809^{* * *}$ \\
Panel B : Female & $(0.083)$ & $(0.061)$ \\
& & \\
$55-59$ & 0.000 & 0.000 \\
$60-64$ & $(-)$ & $(-)$ \\
& 0.000 & 0.000 \\
$65-74$ & $(-)$ & $(-)$ \\
& $0.768^{* * *}$ & $0.751^{* * *}$ \\
& $(0.051)$ & $(0.069)$ \\
\hline
\end{tabular}

$a_{\text {Standard errors in parentheses; }}{ }^{* * *} \mathrm{p}<0.01,{ }^{* *} \mathrm{p}<0.05,{ }^{*} \mathrm{p}<0.1$.

Government and public institutions credibility in Bolivia is very low. Inefficiency, nepotism and corruption all contribute to the erosion of this credibility. The period between the original creation of this program in 1997 and 2007 has been particularly complex for the country at the political and social level. Throughout these 10 years, the government administration changed 7 times, 6 
different presidents took office, and Bolivida was restructured 3 different times. ${ }^{3}$ In particular, at the time of the analysis, the continuation and fiscal sustainability of the program were highly uncertain (Gamboa-Rivera, 2006). Consequently, I claim that potential anticipation of the pension income (and therefore ex-ante adjustments in household structures and borrowings by families) is implausible in my context.

\section{Data, Sample, and Survey Design}

The data consist of two nationally representative cross sectional Living Standards Measurement Study Surveys (LSMS) collected in 2000 and 2001 by the Bolivian National Institute of Statistics (INE). The surveys include a comprehensive socioeconomic module, Bolivida receipt information at the individual level, and detailed educational expenditures for all members in the household that are at least 6 years old. ${ }^{4}$

The sample comprises all school-age children that live in households with at least one person in the age-range of 55 to 74 (Bolivida eligibility age is 65). The school-age range considered is 6 to 13 years old as the minimum legal working age in Bolivia is $14 .^{5}$ The sample excludes all households that do not have any member in the labor market and those whose total reported income is missing. Non-relatives and domestic non-relative workers living in the household are excluded. Observations that belong to the top 1 percent of the income and educational-expenditure distributions are also excluded. The sample includes 1,380 school-age children and 520 eligible elders distributed among 886 households.

The surveys use a stratified two-stage sampling. The sampling frames for the Primary Sampling Units (PSU) and Ultimate Sampling Units (USU) are the lists of Census enumeration areas and dwellings, respectively. Geographical regions and population agglomeration are used for the explicit stratification. Proportion of households classified as poor and average consumption expenditure are used for the implicit stratification. The sampling frame for the baseline survey was constructed on the basis of the 1992 Census enumeration areas list. The followup survey uses an updated sampling frame that was constructed upon revised cartographic information compiled for the 2001 Census. The implications of having surveys coming from two different sampling frames are discussed later in Section 6.3.

Table 3 reports selected summary statistics by ethnicity and gender of the

\footnotetext{
${ }^{3}$ In 2007, Bolivida was once again restructured and turned into Renta Dignidad.

${ }^{4}$ Approximately 18 percent of the Bolivian households are three-generations extended households.

${ }^{5}$ The minimum legal working age is regulated by "Ley General del Trabajo" of December 8th, 1942, and "Decreto Supremo" of August 4th, 1940.
} 


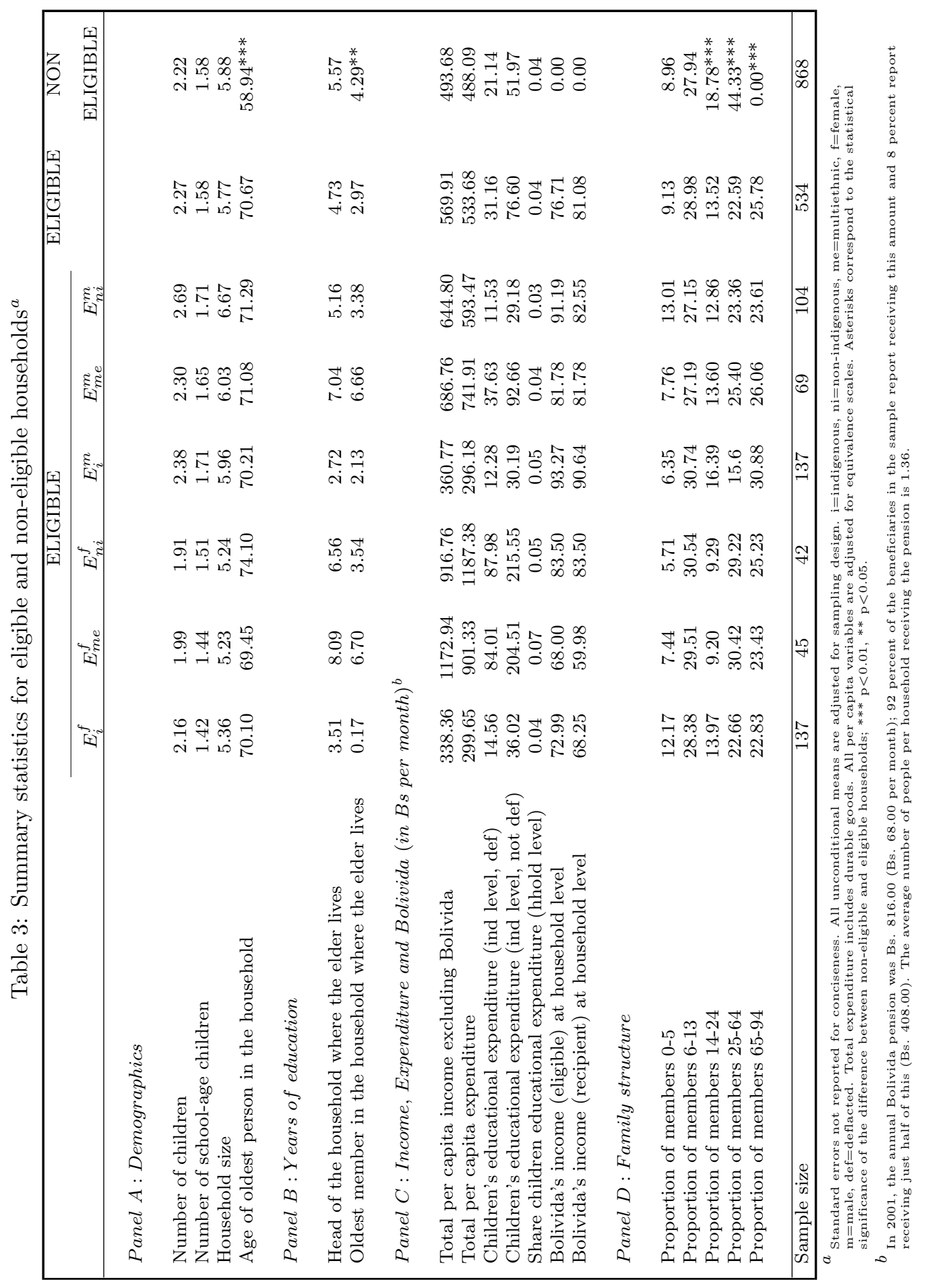


potential recipient. On average, families living with an eligible elder are not too different from those living with a soon-to-be eligible elder. As expected, noneligible and eligible households have different family structures (as the former have on average younger members). Eligible households are slightly smaller and have slightly more children than the non-eligibles ones (though both have the same number of school-age children). Years of schooling of the oldest-member in the household vary considerably across ethnicities and gender. Educational gender gaps among indigenous people are particularly large. Children's educational expenditure are to some extent higher among eligible households, but this difference is not statistically significant at the standard levels. Finally, both, eligible and non-eligible families, allocate approximately 4 percent of their total income on children's schooling expenditures.

\section{The Bolivian Indigenous Population}

The identification of indigenous people in Bolivia is not simple (Psacharopoulos and Patrinos, 1994). Social class and ethnic elements are very interrelated and, thus, are difficult to disentangle. In the context of this paper, the definition of indigenous people is critical for the analysis. Nonetheless many studies have used language spoken for classification, this condition is neither necessary nor sufficient to make a good categorization of indigenous people in the case of Bolivia (Ine and Maipo, 2003).

In general, information used to define indigenous people include a set of ethnolinguistic characteristics. ${ }^{6}$ The surveys used in this paper include three questions aimed at identifying ethnic groups: (i) Do you consider yourself as belonging to an indigenous group?; (ii) What languages do you speak?; (iii) As a child, in what language did you first learn to speak?. The first two questions are collected exclusively for household members that are at least 12 years old, and the third one is collected for all members in the household. The tabulation of these three questions for my sample are reported in Table 4 that shows that the percentage of indigenous people in Bolivia varies considerably upon the criterion selected for classification.

Table 4: Alternative criteria to identify the indigenous population ${ }^{a}$

\begin{tabular}{|lc|}
\hline & $\%$ \\
\hline Self reported as belonging to an indigenous group & 56.38 \\
First language currently spoken is an indigenous language & 54.27 \\
Language in which first learned to speak is an indigenous one & 41.58 \\
\hline$a$
\end{tabular}

$a^{a}$ Calculations include only people 12 years old and older.

\footnotetext{
${ }^{6}$ Ethnolinguistics refers to the study of language within ethnic groups or, more generally, to the relationship between language and culture.
} 
Molina and Albó (2006) use the above three criteria to construct an ethnolinguistic matrix for Bolivia. Their matrix includes 8 ethnolinguistic conditions which weights self-perception more heavily among the three of them (as they consider this the most important criterion to determine ethnicity). I construct this ethnolinguistic matrix for my sample and use it to create an index of indigenism as Table 5 describes. Table 5 shows that nonetheless the Bolivian population is a multiethnic society, close to 70 percent of the population is located at either extreme of the distribution. To be conservative, the approach I adopt in this paper is to classify people across 3 mutually exclusive ethnic groups. Specifically, I classify people as non-indigenous if the index of indigenism is equal 1 , as indigenous if the index is equal to 8 , and as multiethnic otherwise.

Table 5: Ethnolinguistic condition in Bolivia ${ }^{a}$

\begin{tabular}{|ccccc|}
\hline $\begin{array}{c}\text { Index of } \\
\text { indigenism }\end{array}$ & $\begin{array}{c}\text { Self } \\
\text { identification }\end{array}$ & $\begin{array}{c}\text { First language } \\
\text { spoken }\end{array}$ & $\begin{array}{c}\text { Language } \\
\text { as a child }\end{array}$ & $\%$ \\
\hline 1 & no & no & no & 33.7 \\
2 & no & no & yes & 0.00 \\
3 & no & yes & no & 4.04 \\
4 & no & yes & yes & 2.74 \\
5 & yes & no & no & 12.85 \\
6 & yes & no & yes & 0.08 \\
7 & yes & yes & no & 9.82 \\
8 & yes & yes & yes & 36.77 \\
\hline &
\end{tabular}

\section{Estimating the effect of Bolivida on children's educational expenditure}

\subsection{Identification strategy}

Figure 1 illustrates the identification strategy. The conditional probability of being eligible jumps from 0 to 1 at the cutoff value (presenting a large discontinuity for actual beneficiaries). As age is plausibly hard to manipulate, families are unlikely to strategically locate themselves around the eligibility age. Consequently, the main assumption behind the regression discontinuity design (RDD) holds (e.g. Imbens and Lemieux (2008)), and it is used to identify average Bolivida's intent-to-treat effects on children's schooling expenditures. ${ }^{7}$

I am not estimating average treatment effects on the treated as the use of

\footnotetext{
${ }^{7}$ The density of age around the cutoff looks fairly symmetric; this supports the validity of the assumption.
} 
the beneficiary variable in this setup is problematic. Table 2 presents evidence that the pension receipt might be endogenous. It is not clear why differences between actual and estimated beneficiaries arise. It is possible, for instance, to devise a scenario in which deficiencies in the personal identification documentation system, lack of available funds to cover the whole targeted population, or distance to financial centers are constraining eligible members to become recipients. ${ }^{8}$ As these constraining mechanisms are unclear, I find it more appealing to focus on potential beneficiaries.

Figure 1: Elder's probability of receiving Bolivida

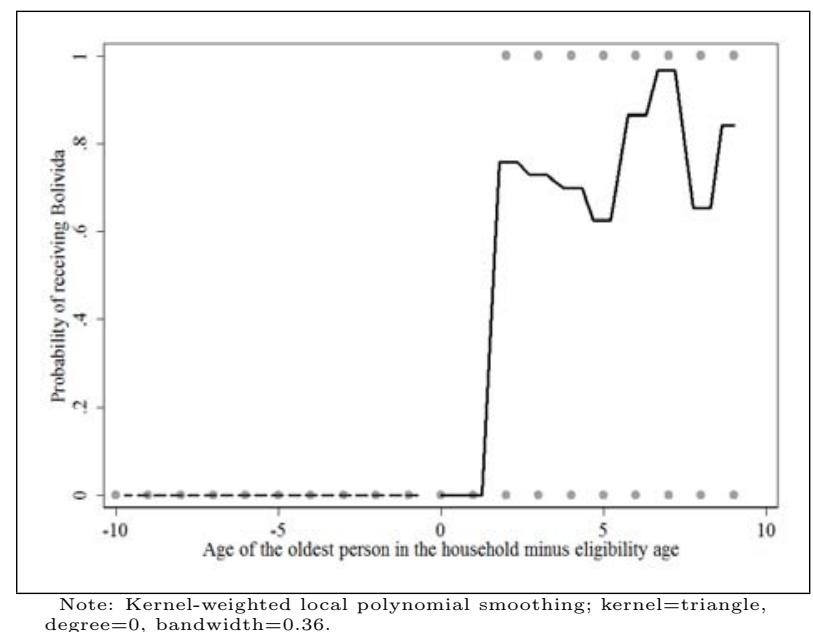

Ideally, I would like to compare people on the age range 64 to 65 . My small sample size however called for a larger extrapolation than originally wished for. A bandwidth of 20 years (10 above and 10 below the cutoff point) is used in the final specification and irremediably requires trading-off precision for bias. I add covariates to the basic specification of my model therefore in the hope that their correlation with schooling expenditure eliminates some of this bias. The sensitivity of the results to the choice of bandwidth is addressed in Section 6.5.

Figure 2 presents the conditional expectation of children's schooling expenditures as a function of the age of the oldest person living in the household. The smoothing is performed separately for Bolivida families (i.e. those with at least one recipient member) and non-Bolivida families (i.e. those with no recipient members). The graph makes clear that having an eligible member increases children's educational expenditure if and only if the person is an actual Bolivida recipient. Next, I parameterize these relationships in order quantify the effect of Bolivia on children's educational expenditure.

\footnotetext{
${ }^{8}$ Even in the case that these constraining mechanisms were clear, the question of whether eligible non-recipient members are an appropriate control group for beneficiaries remains open.
} 
Figure 2: Conditional mean of educational expenditures

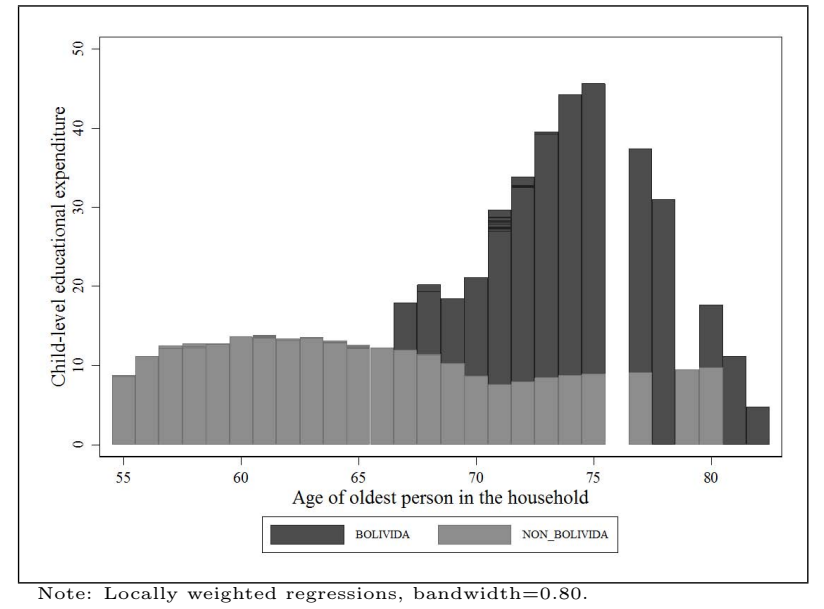

\subsection{Model}

Consider the following model describing the logarithm of schooling expenditures $y$ associated with a given child i living in household h:

$$
y_{i h}=\beta_{o}+E_{h}^{\prime} \eta+f\left(X_{i}, Z_{h}\right)+\epsilon_{i h}
$$

where $y$ is a scalar including matriculation fees, uniforms, textbooks, stationary, copies, tuition fees, transportation, contributions to parent-teacher's organizations (PTOs) to pay for teachers, and contributions to PTOs to improve school infrastructure ${ }^{9} E_{h}$ is a vector of household-specific eligibility indicators variables (equal to one if the elder is eligible and zero if the elder is soon-to-be eligible); $X_{i}$ and $Z_{h}$ are vectors of controls at child and household level, respectively; and $\epsilon_{i h}$ is a normally distributed error disturbance.

Child-level controls entering through the function $f($.$) include sex, mother's$ and father's years of education, age cohort dummies, and indicator variables for whether the mother/father is present, whether the child was enrolled at school, whether the school is public, and whether the eligible member is one of the parents. ${ }^{10}$ Household-level controls include the logarithm of household size, the proportion of household members on age-ranges 0-5, 6-13, 14-24, 25-64 and 6594 , head's years of education, oldest member's years of education, and elder's age

\footnotetext{
${ }^{9}$ Schooling expenditure is deflated by educational CPIs at Departamento-level (main geographical division, $1991=100)$. Disaggregated CPI information by type of expenditure is only available for 3 out of the 9 Departamentos in Bolivia; for the six with missing information I use a national average.

${ }^{10}$ An enrollment dummy is used instead of an attendance dummy to avoid measurement error (the survey was collected in November which coincides with the end of the school year).
} 
cohort indicators. The specification also includes departamento-province-urban fixed effects.

I am not including household income excluding Bolivida as covariate as I want to focus on the total effect of Bolivida on schooling expenditure (i.e. my hypothesis is that Bolivida affects income and thereafter income affects human capital investments). As age is the only eligibility rule, once this is controlled for, controlling for income becomes optional and it only changes the interpretation of the results (e.g. Lee (2005)). Moreover, household income is involved in the determination of the sampling frame and therefore its inclusion as predictor (when the survey design is incorporated, as it is in my case) might introduce bias (e.g. Dumouchel and Duncan (1983) or Winship and Radbill (1994)). Nonetheless, an alternative specification including exogenous income as explanatory variable is presented in Section 6.5.

My hypothesis is that Bolivida leads to heterogenous impacts on schooling expenditures across gender and ethnicity. A way to explicitly incorporate these heterogeneity into the model is to rewrite Equation (1) into a two-stage generalized linear random coefficient model. ${ }^{11}$ As my data is clustered (children nested within households), using a mixed model is appealing as it further allows me to include dependence among schooling expenditures for children living in the same household. Specifically, level-1 model can be written as:

$$
y_{i h}=\beta_{o}+E_{h}^{\prime} \eta_{h}+f\left(X_{i}, Z_{h}\right)+\epsilon_{i h} \quad \epsilon_{i h} \sim N(0, \Lambda)
$$

where the slopes $\eta_{h}$ are household specific coefficients. The between-household variability of the slopes is modeled using the following level-2 model:

$$
\eta_{h}=\gamma_{o o}+K_{h}^{\prime} \theta+\zeta_{h} \quad \zeta_{h} \sim N(0, \Psi)
$$

where $K_{h}$ is a categorical variable indicating the gender and ethnicity of the elder, and $\zeta_{h}$ is independent over households and with $\epsilon_{i h}$. Substituting level-2 into the level-1 model, I obtain the final reduced-form model:

$$
y_{i h}=\left(E_{h}^{\prime} * K_{h}\right) \theta+g\left(X_{i}, Z_{h}\right)+v_{i h}
$$

where $v_{i h}=\epsilon_{i h}+E_{h}^{\prime} \zeta_{h}$ and $g\left(X_{i}, Z_{h}\right)=\beta_{0}+E_{h}^{\prime} \gamma_{o o}+f\left(X_{i}, Z_{h}\right)$.

Besides the main assumption that families are not able to strategically manipulate elder member's age, four more conditions need to hold for $\eta_{h}$ to be informative about the effect of Bolivida on children's schooling expenditures.

\footnotetext{
${ }^{11}$ I am using a two-stage formulation of a generalized linear mixed model not to be confused with a two-level hierarchical generalized linear model.
} 
First, the indicator for eligibility must predict Bolivida participation after controlling for age. This condition holds as was shown in Table 2. Second, age should not be correlated with eligibility to other programs that simultaneously might have affected children's outcomes. In Bolivia, at the time of the analysis, there weren't any children's programs implemented on a national scale. Consequently, overlapping in the eligibility rules is not a potential source of bias. Third, unobserved confounders should be orthogonal to elder's gender and ethnicity. This condition holds by construction as age is the only Bolivida eligibility rule. Fourth, conditional on eligibility, household structure and schooling expenditures must be uncorrelated. Section 3's discussion should make it clear that this correlation is highly unlikely. Formally, these conditions can be written as $E\left(E_{h} \zeta_{h}\right)=0$ and $E\left(E_{h} \epsilon_{i h}\right)=0$.

\subsection{Estimation}

Following Hoddinott and Skoufias (2004) and Borooah and Iyer (2005), regressions are not estimated using a differences-in-differences (DiD) approach but rather a combination of RDD and before-after (BA) design. That is, they are estimated separately for before and after Bolivida and, hereafter, conditional means are compared to assess the impact of the program. Pooling the cross sections is unfeasible in my setup (unless a reweighing scheme is considered, e.g. Pfefferman (1993) and Binder and Roberts (1993)) as both surveys come two from different sampling frames (see Section 4). Unfortunately, I cannot carry out a reweighing scheme with the information that is publicly available. As far as the estimation method, I use maximum likelihood with adaptive quadrature as method of integration (Rabe-Hesketh, Skrondal, and Pickles, 2002).

\subsection{Results}

Table 6 reports the heterogenous impacts of Bolivida on children's educational expenditure by ethnicity and gender of the potential beneficiary. The estimated parameters are reported separately for years 2000 and 2001. Before Bolivida, as expected, eligibility indicators have small and non-significant effects on human capital investments (except for indigenous males). After Bolivida, conversely, women's eligibility indicators have large and significant effects on children's schooling expenditures. The differences in the conditional means for both years are reported in column (3), and present strong evidence that Bolivida transfers led to improvements on children's human capital investments. These improvements are remarkably heterogenous across gender and ethnicity. In particular, conditional on eligibility, non-indigenous women invest more on their children's education than their indigenous counterparts. Specifically, women's eligibility increases schooling expenditure by 56 percent on average among indigenous, by 60 percent among multiethnic, and by 91 percent among non-indigenous. 


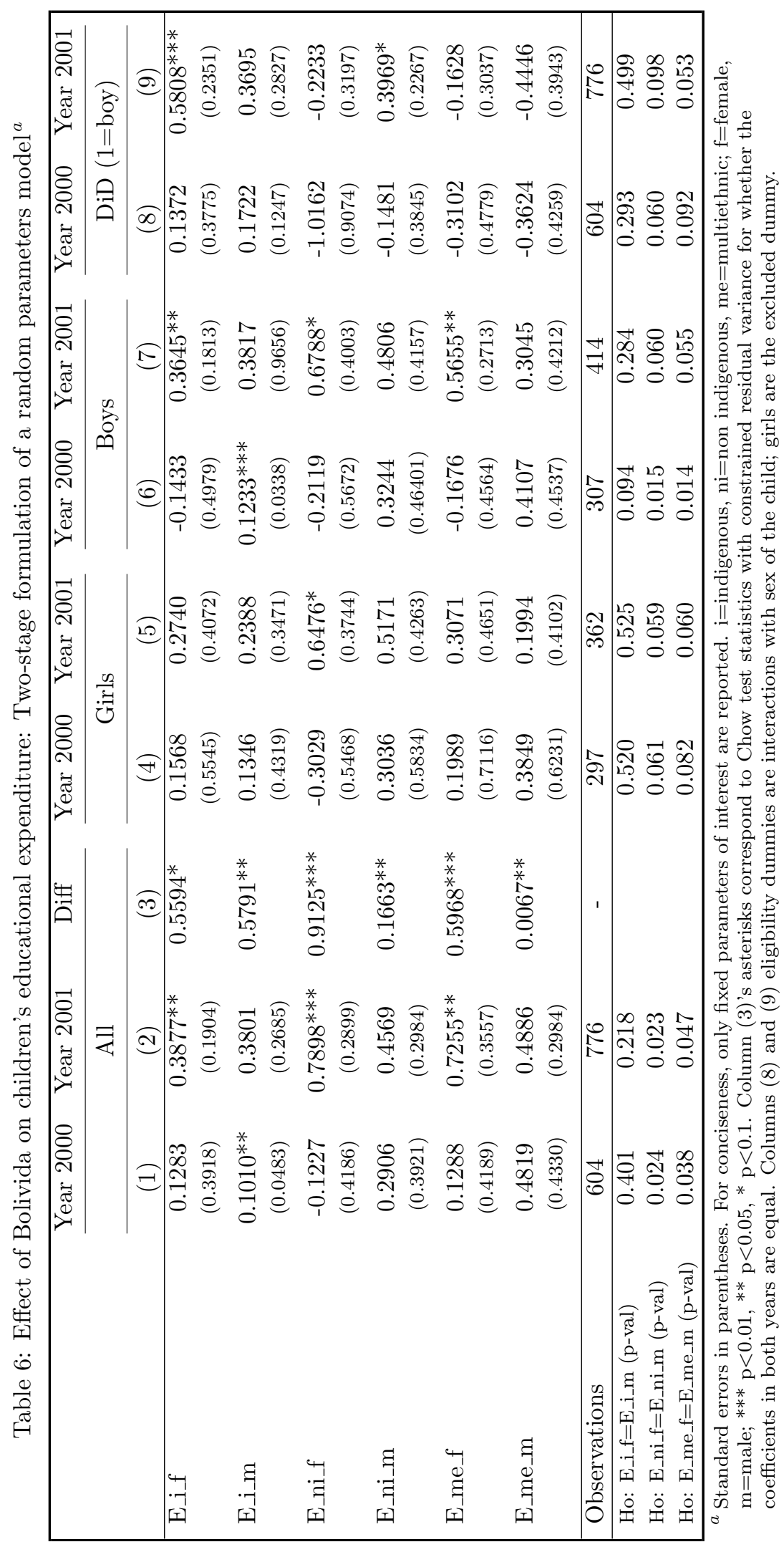


Men's eligibility also increases schooling expenditures but these increases are not statistically significant at the standard levels (the increases are in the order of $0.1,17$, and 58 percent, for multiethnic, non-indigenous, and indigenous, respectively).

The lower panel in Table 6 tests whether the marginal propensity to use Bolivida income differs across gender within ethnic cohorts, i.e. it tests whether male and female allocations within indigenous, multiethnic, and non-indigenous cohorts are equal. Results confirm that non-indigenous women have more power (autonomy) in the allocation of resources as compared to their indigenous counterparts. This therefore presents evidence that cultural factors play a role in the decision-making process of human capital investments. In particular, cultural factors derive in different rules for the allocation of resources within households across ethnic groups.

Hitherto, it was assumed that sex of the child affected the conditional mean of educational expenditure exclusively as a covariate. Next, I estimate the average effects of eligibility for girls and boys separately. ${ }^{12}$ These coefficients are reported in columns (4) to (7) of Table 6 . By looking at the estimated parameters it becomes clear that Bolivida has mainly impacted boys. To confirm these results, I use an alternative DiD specification which uses interactions between eligibility status and sex of the child for the whole sample. ${ }^{13}$ These estimates are reported in columns (8) and (9). They show that indigenous people tend to prioritize boys' schooling expenditures, while non-indigenous respond to samegender preferences (i.e. all other things constant, women (men) invest more on girls' (boys') education). This therefore presents evidence of discrimination against human capital investments on girls among indigenous households.

\subsection{Extensions}

Table 7 presents alternative specifications and estimation methods to assess the robustness of the previous results, and extend some of the previous findings. Column (1) reports the original estimates to be used as benchmark. For conciseness, only estimates for the year 2001 are reported. Column (2) presents the estimated coefficients including household income net of Bolivida as covariate. $^{14}$ Interestingly, with this alternative specification, all men's eligibility

\footnotetext{
${ }^{12}$ It would also be interesting to estimate the model using child ethnicities' sub-samples. However, this is not possible as not all variables used in the classification of ethnic groups were collected for children under the age of 12 (see Section 5).

${ }^{13} \mathrm{My}$ original specification only allowed eligibility to vary over sex-child cohorts. However, results suggested that the slopes of the additional covariates needed to vary as well. The final specification of the DiD therefore includes interactions of sex of the child and all of the fixed parameters (except for geographical fixed effects and age-cohort dummies), along with their corresponding main effects.

${ }^{14}$ The annual income and educational expenditures are adjusted to monthly averages as Bolivida payments were received throughout the year (see footnote 2), and information on
} 


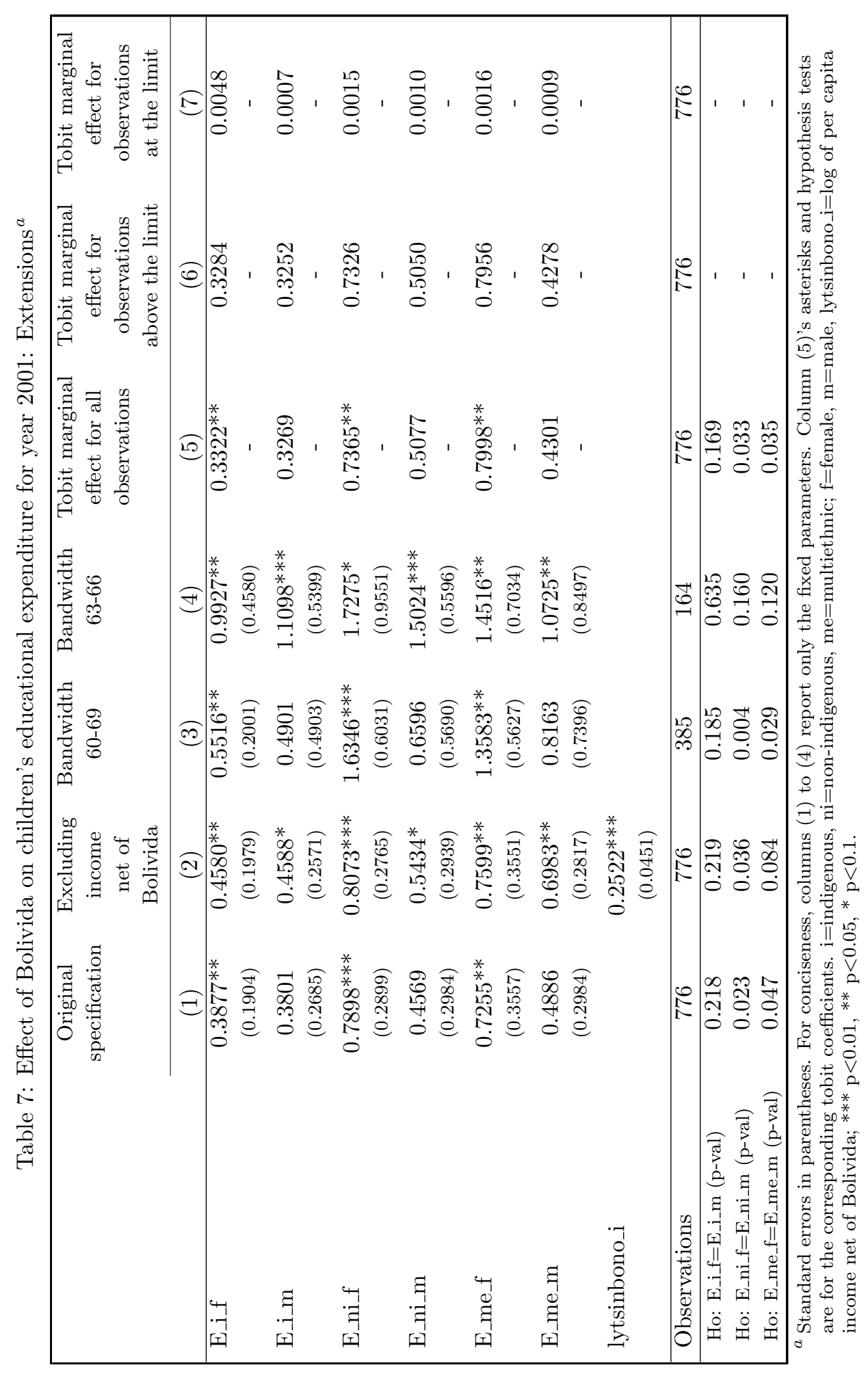


coefficients turn out significant. However, these estimates are potentially biased as explained in Section 6.2.

Columns (3) and (4) present estimates using alternative bandwidths. A major concern in RDD is the high sensitivity of the estimates to the choice of bandwidth. In my case, estimates become larger as the bandwidth goes to zero, suggesting that the impacts of Bolivida might be even higher that the ones previously reported. However, it is reassuring that the patterns of allocation across gender and ethnicity remain all unchanged.

Column (5) reports the marginal effects of a censored model estimated to account for the fact that a non-trivial proportion of school-age children in the sample report zero educational expenditures (11 percent). All estimates follow closely those from the original specification. ${ }^{15}$ Next, I use the McDonald Moffitt technique for censored models with lower bounds to break down the impact of Bolivida (McDonald and Moffitt (1980)). This methodology allows to decompose the marginal effects of the tobit coefficients into the portion caused by observations above the limit (children that before Bolivida were already enrolled in school) and observations at the limit (children that before Bolivida were not enrolled in school). Results, shown in columns (6) and (7), suggest that the average effect of Bolivida is mainly because of the effect on the enrolled children. The effect of children not previously enrolled in school, on Bolivida's effect is minimal, as only few of them get to move across the limit as a result of the program.

Finally, as Bolivida does not seem to be effective at enrolling children at school, I estimate the original reduced-form model specification for each of the components of schooling expenditure. The objective is to get some insight at the specific investments being affected by the program. Estimates (not reported in the paper) suggest that pension income is mainly being invested on contributions to PTOs to pay for teachers and in matriculation fees. ${ }^{16}$ Interestingly, textbooks, transportation, and stationary are investments only considered profitable (and therefore worthwhile investing in) by eligible women.

\section{Conclusions}

This paper uses a quasi-experimental estimator under a RDD and BA framework to study intent-to-teat effects of Bolivida on children's human capital

the time of the receipt is not available in the survey. The income excluding the pension is additionally adjusted for economies of scale in the households. Following World Bank (2003): Adult Equivalence Scales $(\mathrm{AES})=1+0.7($ adults -1$)+0.5$ children.

${ }^{15}$ The conditional moment test of normally distributed disturbances (using a parametric bootstrap for the critical values) cannot be rejected at the 1 percent level (e.g. Skeels and Vella (1999) and Drukker (2002)).

${ }^{16}$ As I do not have a panel, I do not find appealing going further to analyze whether Bolivida crowded children out from public to private schools. 
investments. I find that women are more effective at promoting human capital investments and that, on average, indigenous households tend to prioritize boys' education. Having a eligible woman in the household increases children's schooling expenditures by approximately 56 to 91 percent, depending on the ethnicity of the recipient. Pension income in the hands of indigenous has a smaller impact on human capital investments than analogous income in the hands of non-indigenous. The average effects of Bolivida are mainly the result of investments on children already enrolled in school before the program started. The impact of Bolivida on children not previously enrolled in school is very limited as eligible members are likely to allocate this source of income to other priority expenses if binding budget constraints in their households are the reason why these children are not enrolled in school.

The main contribution of the paper is presenting evidence that income allocation mechanisms are highly dependent on cultural factors. Specifically, culture counts in the decision making process of human capital investments in Bolivia. However, I am agnostic about the exact allocation mechanisms by which Bolivida causes changes in children's schooling expenditures and this remains open for future research. 


\section{References}

Barja, G., J. Monterrey, and S. Villarroel (2004): "Bolivia: Impacts of shocks and poverty policy on household welfare," Maestrías para el Desarrollo, Universidad Católica Boliviana.

Barja, G., and M. Urquiola (2003): "Capitalization and Privatization in Bolivia: An Approximation to an Evaluation," Maestrías para el Desarrollo, Universidad Católica Boliviana.

Binder, D., And G. Roberts (1993): "Design-based and Model-based Methods for Estimating Model Parameters," in Analysis of Survey Data, ed. by R. Chambers, and C. Skinner. Wiley, Chichester, 29-48.

Borooah, V., And S. Iyer (2005): "Vidya, Veda, and Varna: The influence of religion and caste on education in rural India," The Journal of Development Studies, 41(8), 1369-1404.

Case, A., and A. Deaton (1998): "Large Cash Transfers to the Elderly in South Africa," Economic Journal, 108(450), 1330-1361.

de Carvalho Filho, I. E. (2000): "Household income as a determinant of Child labor and school enrollment in Brazil: Evidence from a Social Security Reform," Mimeograph, The RIS Consulting Group LLC.

Dowers, K., S. Fassina, and S. Pettinato (2001): "Pension reform in Small Emerging Economies: Issues and Challenges," Sustainable Development Department Technical Papers Series. Inter-American Development Bank. Washington D.C.

Drukker, D. M. (2002): "Bootstrapping a conditional moments test for normality after tobit estimation," Stata Journal, 2(2), 125-139.

Duflo, E. (2003): "Grandmothers and Granddaughters: Old Age Pensions and Intra-Household Allocation in South Africa," World Bank Economic Review, $17(1), 1-25$.

Dumouchel, W. H., and G. J. Duncan (1983): "Using Sample Survey Weights in Multiple Regression Analyses of Stratified Samples," Journal of the American Statistical Association, 78(383), 535-543.

Edmonds, E. (2006): "Child Labor and Schooling Responses to Anticipated Income in South Africa," Journal of Development Economics, 81(2), 386-414.

Gambon-Rivera, R. (2006): "Evaluación de la Sostenibilidad del Pago del Bonosol," Análisis Económico, 21, Unidad de Análisis de Políticas Sociales y Económicas. La Paz- Bolivia.

Gasparini, L., M. Marchionni, and F. Gutierrez (2004): "Simulating Income Distribution Changes in Bolivia: a Microeconometric Approach," Working Papers 0012, CEDLAS, Universidad Nacional de La Plata. 
Hoddinott, J., And E. Skoufias (2004): "The impact of PROGRESA on Food Consumption," Economic Development and Cultural Change, 53(1), 3761.

Imbens, G. W., And T. Lemieux (2008): "Regression discontinuity designs: A guide to practice," Journal of Econometrics, 127(2), 615-635.

INE, AND MAIPO (2003): "Bolivia, características sociodemográficas de la población indígena," Instituto Nacional de Estadística y Ministerio de Asuntos Indígenas y Pueblos Originarios. La Paz, Bolivia.

Larson, B., O. Harris, and E. TAndeter (1995): Ethnicity, Markets, and Migration in the Andes: At the Crossroads of History and Anthropology. Duke University Press.

LeE, M. J. (2005): Micro-Econometrics for Policy, Program, and Treatment Effects (Advanced Texts in Econometrics). Oxford University Press, USA.

Martínez, S. (2004): "Pensions, Poverty and Household Investments in Bolivia," Mimeograph, University of Berkeley, Department of Economics.

McDonald, J., and R. Moffitt (1980): "The Uses of Tobit Analysis," The Review of Economics and Statistics, 62(2), 318-321.

Molina, R., And X. Albó (2006): "Gama étnico y linguística de la población Boliviana," La Paz - Sistema de las Naciones Unidas en Bolivia.

Pfefferman, D. (1993): "The Role of Sampling Weights when Modeling Survey Data," International Statistical Review, 61(2), 317-3 37.

Psacharopoulos, G. (1993): "Ethnicity, education, and earnings in Bolivia and Guatemala," Comparative Education Review, 37(1), 9-20.

Psacharopoulos, G., and H. Patrinos (1994): "Indigenous People and Poverty in Latin America: An Empirical Analysis," The World Bank, Washington D.C.

Rabe-Hesketh, S., A. Skrondal, And A. Pickles (2002): "Reliable estimation of generalized linear mixed models using adaptive quadrature," Stata Journal, 2(1), 1-21.

Rofman, R. (2006): "The Pension System: Reforms of the Reform," in Bolivia: Public Policy Options for the Well-being of All, ed. by V. Fretes-Cibils, M. Giugale, and C. Luff. The World Bank Publications, Washington DC.

Skeels, C. L., And F. Vella (1999): "A Monte Carlo investigation of the sampling behavior of conditional moment tests in Tobit and Probit models," Journal of Econometrics, 92(2), 275-294.

Stephenson, M. (1999): Gender and Modernity in Andean Bolivia. University of Texas Press. 
UdAPE (2006): "Pueblos Indígenas Originarios y Objetivos de Desarrollo del Milenio," Unidad de Análisis de Políticas Sociales y Económicas. La PazBolivia.

Udape, and Unicef (2005): "Bolivia: Equidad y Derechos de la Niñez. Índice Municipal de Desarrollo de la Infancia, Niñez y Adolescencia," UDAPE, La Paz, Bolivia.

von Gersdorff, H. (1997): "The Bolivian Pension Reform: Innovative Solutions to Common Problems," World Bank Policy Research Working Paper 1832, The World Bank, Washington D.C.

Winship, C., And L. Radbill (1994): "Sampling Weights and Regression Analysis," Sociological Methods Research, 23(2), 230-257.

World Bank (2003): "Poverty Manual," The World Bank, Washington D.C.

Yanez-Pagans, P., and F. Landa (2007): "Informe Especial de Informalidad en Bolivia," Mimeograph. Unidad de Análisis de Políticas Sociales y Económicas. La Paz- Bolivia. 